NASA Technical Memorandum 102579

\title{
Multi-Objective Shape and Material Optimization of Composite Structures Including Damping
}

\author{
D.A. Saravanos \\ Case Western Reserve University \\ Cleveland, Ohio
}

and

C.C. Chamis

Lewis Research Center

Cleveland, Ohio

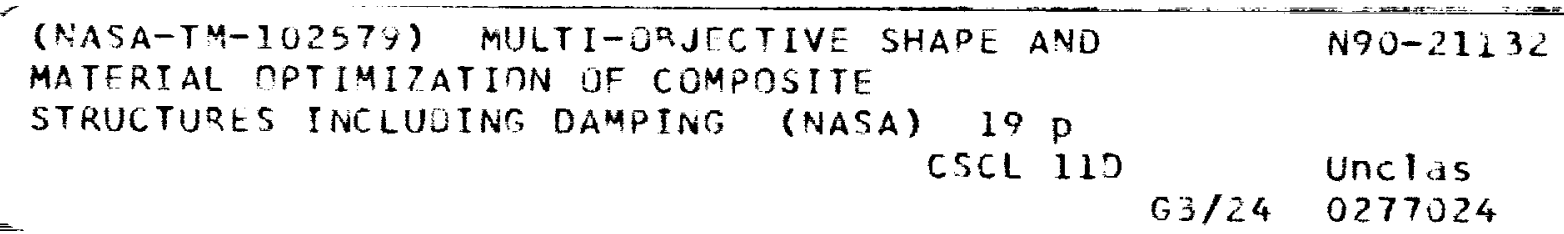
G3/24 0277024

Prepared for the

31st Structures, Structural Dynamics, and Materials Conference

$=$ cosporisored by the AIAA, ASME, ASCE, AHS, and ASC Long Beach, California, April 2-4, 1990 


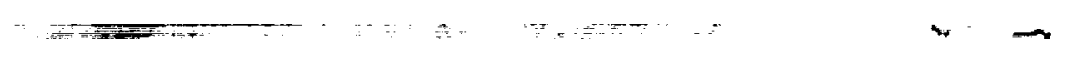

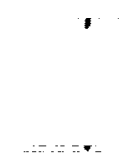




\title{
MULTI-OBJECTIVE SHAPE AND MATERIAL OPTIMIZATION \\ OF COMPOSITE STRUCTURES INCLUDING DAMPINC
}

\author{
D.A. Saravanos* \\ Case Western Reserve University \\ Cleveland, Ohio 44106 \\ and \\ C.C. Chamis * \\ National Aeronautics and Space Administration \\ Lewis Research Center \\ Cleveland, Ohio 44135
}

\begin{abstract}
A multi-objective optimal design methodology is developed for light-weight, low-cost composite structures of improved dynamic performance. The design objectives include minimization of resonance amplitudes (or maximization of modal damping), weight, and material cost. The design vector includes micromechanics, laminate, and structural shape parameters. Performance constraints are imposed on static displacements, dynamic amplitudes, and natural frequencies. The effects of damping on the dynamics of composite structures are incorporated. Preliminary applications on a cantilever composite beam illustrated that only the proposed multi-objective optimization, as opposed to single objective functions, simultaneously improved all objectives. The significance of composite damping in the design of advanced composite structures was also demonstrated, indicating that design methods based on undamped dynamics may fail to improve the dynamic performance near resonances.
\end{abstract}

\section{Nomenclature}

$A$

$[C],[c]$

E

$f$

$f_{d}$

"NASA Resident Research Associate at Lewis Research Center; member AIAA.

* * Senior Research Scientist; member AIAA.
Area.

Global and modal damping matrices.

Normal modulus.

Frequency.

Damped frequency. 


$\begin{array}{ll}\mathbf{F}(\mathbf{z}) & \text { Objective functions. } \\ G & \text { Shear modulus. } \\ \mathbf{G}(\mathbf{z}) \dagger & \text { Inequality constraints. } \\ h & \text { Thickness. } \\ \mathbf{H}(\mathbf{z}) & \text { Equality constraints. } \\ {[K],[k]} & \text { Global and modal stiffness matrices. } \\ k & \text { Volume ratio. } \\ {[M],[m]} & \text { Global and modal mass matrices. } \\ \mathbf{P}, \mathbf{p} & \text { Global and modal excitation force. } \\ \mathbf{q} & \text { Modal vector. } \\ t & \text { Time. } \\ \mathbf{u} & \text { Displacement vector. } \\ U & \text { Dynamic amplitude. } \\ \mathbf{v} & \text { Weighting coefficients. } \\ V_{f} & \text { Average fiber volume per unit area. } \\ w, \delta w & \text { Stored and dissipated specific strain energies. } \\ W, \delta W & \text { Stored and dissipated strain energies. } \\ \mathbf{z} & \text { Design vector. } \\ \theta & \text { Fiber orientation angle. } \\ \nu & \text { Poisson's ratio. } \\ \rho & \text { Mass density. } \\ \sigma & \text { Stress. } \\ \dot{\psi} & \text { Specific damping capacity. } \\ {[\Phi]} & \text { Modal matrix. } \\ & \end{array}$

Subscripts

$e \quad$ Finite element.

$f \quad$ Fiber.

$l \quad$ Ply (on-axis).

L Laminate.

$\dagger$ Bold characters indicate vectors. 


$\begin{array}{ll}m & \text { Matrix. } \\ n & \text { n-th mode. } \\ d & \text { Dynamic. }\end{array}$

Superscripts

$\begin{array}{ll}r & \text { Resonance. } \\ L & \text { Lower. } \\ U & \text { Upper. }\end{array}$

\section{Direction}

11

$n$

$s$

$x, y, z$
Normal longitudinal.

Normal in-plane transverse.

Shear in-plane.

Normal (isotropic material).

Shear (isotropic material).

Structural axes.

\section{Introduction}

Fiber composite materials are widely used in structural applications requiring high stiffness-to-weight and strength-to-weight ratios, as they readily provide high specific moduli, high specific strengths, and tailorable anisotropic elastic properties. A spectrum of design methods has been developed, ranging from basic to optimal tailoring of composite laminates and structures, in order to meet requirements for high performance and light-weight. However, most such design methodologies are primarily based on stiffness and strength tailoring, hence, they can predict good static structural performance, but not necessarily an optimal dynamic performance as they neglect an important dynamic parameter, the damping of composite materials.

Polymer matrix composites are known to exhibit significantly higher damping compared to most common metals. The previously stated requirements for advanced lightweight structures virtually exclude most traditional sources of passive damping, therefore, the option to utilize the damping capacity of polymer-matrix composites appears very attractive. Reported research on the damping of unidirectional composites and laminates ${ }^{1-6}$ 
has shown that the damping of composites is highly- tailorable and is primarily controlled by constituent parameters (fiber/matrix properties, fiber volume ratio), and laminate parameters (ply angles/thicknesses, stacking sequence). Additional research work ${ }^{7}$ demonstrated that the modal damping of composite structures depends also on the structural shape and structural deformation (mode shapes). This work also suggested that properly designed composite structures can provide significant passive damping, and they may further improve the dynamic performance and fatigue endurance by attenuating undesirable elasto-dynamic phenomena such as structural resonances, overshooting, and long settling times. The previous studies have also demonstrated that any increase in damping typically results in decreased stiffness and possibly strength, therefore, any tailoring of the composite material for optimal damped response will be based on trade- offs between damping, stiffness, and strength.

Reported work on the optimization of composite damping is mostly limited on local laminate properties instead of structural ones ${ }^{8-9}$. The authors have reported work on the optimization of the transient and forced dynamic response of composite structures ${ }^{10-11}$. This work is limited to a single objective function and laminate tailoring only, but illustrates that in order to realize full benefits from the damping capacity of composite materials, integrated methodologies for the optimal design of composite structures should be developed entailing: (1) multiple objectives to effectively represent the array of competing design requirements; (2) capability for tailoring the basic composite materials and/or laminate; (3) capability for shape optimization; and (4) design criteria based on the global static and dynamic response of the composite structure.

This paper presents the development of such a formal design method which allows the optimization of composite structures for optimal damped dynamic performance based on multiple objectives. The proposed design objectives are minimization of resonance amplitudes (or maximization of structural damping), minimization of structural weight, and minimization of material cost. The structural damped dynamic response is simulated with finite element analysis. A preliminary evaluation of the methodology on the structural optimization of a cantilever composite beam is presented. The results quantify the importance of structural damping in improving the dynamic performance of composite 
structures, and illustrate the suitability of multiple objectives in the optimal design of composite structures.

\section{Damped Structural Dynamic Response}

Assuming that finite element discretization has been applied, the dynamic response of a structure which is excited by a force $P(t)$ is expressed by the following system of dynamic equations:

$$
[M] \ddot{\mathbf{u}}+[C] \dot{\mathbf{u}}+[K] \mathbf{u}=\mathbf{P}(\mathrm{t})
$$

where $\mathrm{u}$ is the discretized displacement vector. In the case of laminated composite structures, the stiffness, damping, and mass matrices, $[\mathrm{K}],[\mathrm{C}]$, and $[\mathrm{M}]$ respectively, are synthesized utilizing micromechanics, laminate, and structural mechanics theories representing the various material and structural scales in the composite structure.

The related theories for this multi-level simulation of structural composite damping are described in refs. 1,2 , and 7. Analogous theories are utilized for the synthesis of other mechanical properties ${ }^{12}$. At the micromechanics level, the on-axis damping capacities of the basic composite material systems are calculated based on the constituent properties, material microstrücture, fiber volume ratio (FVR), temperature, and moisture. The offaxis damping capacities of the composite plies are calculated at the laminate level, and the local laminate damping matrices are predicted based on on-axis damping values, ply thicknesses, and laminate configuration. The damping contributions of the interlaminar damping layers due to interlaminar shear stress are also incorporated.

The structural modal damping is synthesized by integrating the local laminate damping contributions over the structural volume. The modal specific damping capacity (SDC) of the $\mathrm{n}$-th vibration mode $\psi_{n}$ is:

$$
\psi_{n}=\frac{\int_{A} \delta W_{L n} d A}{\int_{A} W_{L n} d A}
$$

where: $A$ is the structural area; $\delta W_{L n}$ and $W_{L n}$ are respectively the dissipated and maximum stored laminate strain energy distributions of the n-th mode per unit area per cycle. 
Utilizing the finite element discretization scheme proposed in ref. 7 , the modal SDC is finally related to the finite element damping and stiffness matrices, $\left[C_{e}\right]$ and $\left[K_{e}\right]$ respectively:

$$
\psi_{n}=\frac{\sum_{i=1}^{n e l} \frac{1}{2} \mathrm{u}_{e i n}{ }^{T}\left[C_{e i}\right] \mathrm{u}_{e i n}}{\sum_{i=1}^{n e l} \frac{1}{2} \mathrm{u}_{\mathrm{ein}}{ }^{T}\left[K_{e i}\right] \mathrm{u}_{\mathrm{ein}}}
$$

where, nel is the total number of elements, and $\mathbf{u}_{\text {ein }}$ the nodal displacements of the $\mathrm{i}$-th element corresponding to the $\mathrm{n}$-th vibration mode. The dynamic response of the structure is simulated based on modal superposition. The dynamic system in eq. (1) is transferred to the $p \times p$ modal space via the linear transformation $\mathbf{u}=[\boldsymbol{\Phi}] \mathbf{q}$. Assuming proportional damping and utilizing the first $p$ modes, the following set of $p$ uncoupled dynamic equations results:

$$
[m] \ddot{\mathbf{q}}+[c] \dot{\mathbf{q}}+[k] \mathbf{q}=\mathbf{p}(\mathbf{t})
$$

The frequency response of the structure would be,

$$
\mathbf{u}(f)=[\Phi] \mathbf{q}(f)
$$

where $\mathbf{q}(f)$ is the frequency response in the modal space induced by a harmonic force Psin $(2 \pi f t)$ of frequency $f$. A typical frequency response function (FRF) is shown in Fig. 1. The dynamic amplitude $U_{j}$ at a frequency $f$ is the complex magnitude of the displacement $u_{j}(f)$,

$$
U_{j}(f)=\left|u_{j}(f)\right|
$$

The resonance amplitude $U_{j n}^{r}$ at the n-th vibration mode is:

$$
U_{j n}^{r}=\left|u_{j}\left(f_{d n}\right)\right|
$$

where $f_{d n}$ is the $\mathrm{n}$-th damped natural frequency. The dynamic and resonance amplitudes in eqs. (6) and (7) are used as dynamic performance measures. The resonance amplitudes are primarily related to modal damping, and they decrease as the damping increases. Increased modal stiffness will also reduce the respective resonance amplitudes. 


\section{Multi-Objective Optimal Design}

As previously explained, damping is one of the factors that control the dynamic performance of composite structures near resonances. High damping values result in improved vibration control and fatigue endurance. However, increases in composite damping may typically result in stiffness/strength reduction and/or mass addition. Proposed design methods for optimizing the undamped dynamic performance of composite structures will fail to utilize the full potential of composite materials and may increase the dynamic amplitudes near resonances.

The minimization of weight and material cost are also included in the objectives. The material cost is a crucial factor, restricting in many cases the use of composite materials. The distinction between weight and material cost is also stressed. Fiber reinforced composites are non-uniform materials, hence, weight minimization does not correspond to material cost minimization. The design of composite structures for optimal dynamic performance is a multi-objective task, and may be best accomplished as the constrained minimization of multiple objective functions.

A constrained multi-objective problem involving minimization of $l$ objective functions is described in the following mathematical form:

$$
\min \left\{F_{1}(\mathbf{z}), F_{2}(\mathbf{z}), \ldots, F_{l}(\mathbf{z})\right\}
$$

subject to lower and upper bounds on the design vector $z$, inequality constraints $G(z)$, and equality constraints $\mathbf{H}(\mathbf{z})$ :

$$
\begin{gathered}
\mathrm{z}^{\mathrm{L}} \leq \mathrm{z} \leq \mathrm{z}^{\mathrm{U}} \\
\mathrm{G}(\mathrm{z}) \leq 0 \\
\mathrm{H}(\mathbf{z})=0
\end{gathered}
$$

In the rest of the paper, upper and lower values are represented by superscripts $L$ and $U$ respectively. Individual minimizations of each objective function subject to constraint set (9) will result in a set of $l$ suboptima $\mathbf{F}_{1}=\left(F_{1}^{*}, F_{2}, \ldots, F_{l}\right), \mathbf{F}_{2}=\left(F_{1}, F_{2}^{*}, \ldots, F_{l}\right)$, and so forth. These suboptima define a target point $\mathbf{F}^{*}=\left(F_{1}^{*}, F_{2}^{*}, \ldots, F_{l}^{*}\right)$ in the objective function subspace which usually lies in the infeasible domain. Hence, a candidate solution 
may be obtained by finding a feasible point $\mathbf{F}=\left(F_{1}, \ldots, F_{l}\right)$ in the objective function subspace as closely as possible to the target point $\mathbf{F}^{*}$. This is equivalent to minimizing the distance between points $\mathbf{F}$ and $\mathbf{F}^{*}$ subject to constraints (9), that is:

$$
\min \left\|\mathbf{F}_{\mathbf{i}}-\mathbf{F}_{\mathbf{i}}^{*}\right\|
$$

where the symbol ||$\|$ implies an admissible metric. In the present study, a weighted Euclidean metric is chosen for its simplicity and physical meaning. Other metrics may also be utilized, but in general, they are expected to result in different solutions. Hence, the original multi-objective problem becomes a constrained minimization problem of the following scaled objective function:

$$
\min \sum_{i=1}^{l} v_{i} \frac{\left(F_{i}-F_{i}^{*}\right)^{2}}{F_{i}^{* 2}}
$$

subject to constraints (9). The weighting coefficients are represented with $v_{i}$.

In the present method, the design objectives include minimization of: (1) the maximum resonance amplitude $\left(F_{1}=\max \left\{U_{j n}^{r}\right\}\right) ;(2)$ the total structural weight $W\left(F_{2}=W\right)$; and (3) the material cost represented by the average cost of fibers per unit area $P_{f}$ $\left(F_{3}=P_{f}\right)$. The resonance amplitudes are related to modal stiffness, modal damping, and modal mass, hence, the objective function $F_{1}$ will tune the modal stiffness, damping and mass. Alternatively, $F_{1}$ may represent modal damping values. The explicit maximization of modal damping may be preferred in the case if an a-priori unknown dynamic excitation. The use of fiber cost as a measure of the total material cost is justified in view of the very high cost of fibers compared to the cost of matrix. The design vector includes fiber volume ratios (FVRs), ply angles, and shape parameters. The proposed design criteria are then formulated in the following form:

$$
\min \left\{F_{1}, F_{2}, F_{3}\right\}
$$

subject to constraints (9.1), constraints on static deflections $\mathbf{u}_{\mathbf{s}}$,

$$
\mathrm{u}_{\mathrm{s}} \leq \mathrm{u}_{\mathrm{s}}^{\mathrm{U}}
$$


dynamic amplitudes (including dynamic resonance amplitudes),

$$
\begin{gathered}
\mathbf{U}_{\mathrm{d}}(f) \leq \mathbf{U}_{\mathbf{d}}^{\mathrm{U}} \\
\mathbf{U}_{\mathbf{n}}^{\mathbf{r}} \leq \mathbf{U}_{\mathbf{n}}^{\mathrm{r} \mathbf{U}}
\end{gathered}
$$

and natural frequencies $f_{n}$.

$$
\mathbf{f}^{\mathrm{L}} \leq \mathbf{f}_{\mathrm{n}} \leq \mathrm{f}^{\mathrm{U}}
$$

This constrained optimization problem is solved with non-linear programing. In the present paper the modified feasible directions non-linear programing method ${ }^{13}$ is utilized.

\section{Application and Results}

The proposed design method was applied on the optimal tailoring of a cantilever graphite/epoxy composite beam. The initial beam shape ( 6 in long, lin wide, and $0.2 \mathrm{in}$ thick) is shown in Fig. 2a. Typical properties of the composite material in room conditions are shown in Table 1. The SDCs of the fibers and matrix were backcalculated from the respective laminate SDCs reported in ref. 4 . The beam was assumed to operate in room conditions. The composite beam is symmetric consisting of angle-plied sublaminates 1, 2, and 3 in each side. All sublaminates have plies of equal thickness (0.01in). Sublaminate 3 is at the center of the beam. Fig. $2 \mathrm{~b}$ shows the laminate configuration $\left(\left( \pm \theta_{1}\right)_{2} /\left( \pm \theta_{2}\right)_{2} /\left( \pm \theta_{3}\right)\right)_{s}$ for the initial uniform beam thickness. The ply angles $\theta_{i}$ and FVRs $k_{f i}$ of each sublaminate, and the thicknesses $h_{j}$ at $0 \%, 30 \%, 60 \%$, and $100 \%$ (tip) of the beam span were the design variables. The thickness at other sections of the beam was interpolated using a cubic spline fit. It was further assumed that when the thickness of a cross-section was reduced, the inner plies of Sublaminate 3 would first drop, and if necessary, the inner plies of Sublaminates 2 and 1 would drop subsequently. A central ply was dropped when its thickness was reduced to less than $0.005 i n$. In such case the thickness of the adjacent ply was increased by an equal amount to avoid discontinuity. In the opposite case of increased thickness, inner plies of 0.01 in thickness were added to Sublaminate 1 . 
A finite element mesh of 55 nodes and 80 specialty triangular plate elements was utilized. A static transverse out-of-plane ( $y$-axis) force of $5 \mathrm{lbs} / \mathrm{in}$, and a transverse out-ofplane harmonic force of $0.1 \mathrm{lbs} / \mathrm{in}$ amplitude were applied at the tip of the beam. Under this type of dynamic loading, the maximum resonance amplitude at the tip corresponds to the first mode (first out-of-plane bending) $\left(F_{1}=U_{y_{1}}^{r}\right)$. Because a single composite system was assumed, the material cost was replaced by the average fiber volume per unit area $V_{f}$, $\left(F_{3}=V_{f}\right)$. The weighting coefficients in eq. (11) were set equal to unity. Constraints were imposed on the transverse static deflections and on the transverse resonance amplitudes of the first five modes at the tip of the beam. Additional lower bounds were imposed on the first two natural frequencies.

$$
\begin{gathered}
u_{s y} \leq 35 \quad 10^{-3} \mathrm{in} \\
U_{y n}^{r} \leq 0.45 \mathrm{in} \\
f_{1} \geq 400 \mathrm{~Hz} \text { and } f_{2} \geq 1200 \mathrm{~Hz}
\end{gathered}
$$

The following upper and lower bounds were imposed on the design variables:

$$
\begin{aligned}
-90.0^{\circ} \leq \theta_{i} & \leq 90.0^{\circ} \\
0.01 \leq k_{f i} & \leq 0.70 \\
0.04 i n \leq h_{j} & \leq 0.4 i n
\end{aligned}
$$

Table 2 shows the initial reference design, the three suboptimal designs with each objective function individually optimized, and the resultant optimal design of the multiobjective optimization. The unidirectional beam was selected as the initial reference design because it provides the higher bending rigidity. The predicted maximum static deflection, as well as the resonance amplitudes at the tip, natural frequencies, and modal SDCs of the first 3 modes are also shown. As seen in table 2, the initial design violates both frequency constraints, but all optimized designs have natural frequencies in the feasible frequency domain. All optimized designs have non-uniform thickness, being thick at the proximal end and thin at the distal end. Side views of the optimized thickness shapes for each optimization case are plotted in Fig. 3. Also, the static deflection constraints were active only in the minimum-weight design. 
The optimized designs differ in many aspects. The minimization of the resonance tip amplitude $\left(\min F_{1}\right)$ decreased the resonance peak by $65 \%$ with respect to the unidirectional beam. This reduction was attained by a combination of high modal stiffness and damping. The shape optimization resulted in increased weight and material cost (12\%) and redistribution of the material. The near $\mp 27^{\circ}$ ply-angles in the outer two sublaminates contribute to high flexural damping and increased in-plane shear stiffness, while the high FVRs provide out-of-plane flexural stiffness. The inner ply primarily contributes to damping.

The minimum weight design $\left(\min F_{2}\right)$ decreased the weight of the beam by $23 \%$, the material cost by $31 \%$, but also increased the resonance amplitude by $12 \%$ with respect to the initial design. The weight reduction was primarily accomplished by material redistribution, lower ply angles in the outer sublaminate, and lower FVRs in all sublaminates (the fibers have higher density than the matrix). In fact, the inner sublaminate was virtually reduced to pure matrix resulting in a sandwich type laminate configuration. The first modal damping has moderately increased.

The minimum cost design $\left(\min F_{3}\right)$ decreased the material cost by $50 \%$, the structural weight by $15 \%$, and increased the first resonance amplitude by $11 \%$. Interestingly, the ply angles of the two outer sublaminates are $\pm 3.2^{\circ}$ and $\pm 3.7^{\circ}$ respectively, an almost unidirectional configuration, and the FVR's were reduced. The inner sublaminate was again reduced to pure matrix. This laminate tailoring provides the ultimate utilization of the reinforcing fibers. Both natural frequency constraints are active, and the first modal damping of the optimized beam is low.

Clearly, all individual minimizations of each objective function failed to produce simultaneous improvements in all objectives. In contrast, the resultant multi-objective optimal design seems to blend many of the merits of the individual single-objective optimizations, since all objective functions were significantly reduced compared to the initial design. Specifically, the first resonance amplitude was decreased by $60 \%$, the structural weight by $10 \%$, and the material cost by $50 \%$. This clearly illustrates the superiority and suitability of the multi-objective optimal design for composite structures. The optimum laminate 
configuration is composed by an outer $\mp 26^{\circ}$ angle-ply sublaminate of high FVR providing all the stiffness, and two inner sublaminates of virtually pure matrix. It seems likely, that the reduction of Sublaminate 2 to pure matrix was driven by the requirements of high damping and low material cost. Indeed, the present optimal design exhibits the higher value for the first modal SDC, and material cost reduction equal to that obtained by the minimum cost design. This suggests the possibility of utilizing hybrid laminates, and layers of high-damping viscoelastic materials for further improvements.

The frequency response functions at the mid-point of the free-edge of the initial and optimized beams are shown in Fig. 4. The multi- objective optimum design produced the best FRF, while the minimum cost and minimum weight designs the most inferior. This suggests that the incorporation of composite damping was crucial in obtaining these significant improvements in all objective functions illustrating, in this manner, the significance of composite damping in the design of high-performance, light-weight, and low-cost composite structures. Optimal design methodologies neglecting the damping capacity of composite materials and its controllable anisotropy may lead to structures with inferior dynamic performance near the resonance regimes, hence, they may be unsuitable for optimizing the dynamic performance of composite structures.

\section{Summary}

An optimal design methodology for optimizing the dynamic performance of composite structures based on multiple objectives was proposed. The effects of composite damping on the dynamics of composite structures were incorporated. The design objectives included minimization of resonance amplitudes (or maximization of modal damping), minimization of structural weight, and minimization of material cost. Performance constraints were imposed on static displacements, dynamic resonance amplitudes, and natural frequencies. The described method has been integrated into an in-house research code (STAT) [14].

The method was applied on the optimal design of a cantilever composite beam. The multi-objective optimization was proved superior in optimizing the competing requirement for high damping, low weight, and low material cost, and resulted in significant simultaneous improvements in all objective functions. Optimizations with single objective 
functions did not improve all objectives. The obtained results for this primitive structure also illustrated that the damping capacity of composite materials is an important factor in designing light-weight, low-cost composite structures of improved dynamic performance. It was further shown that proposed methods for optimizing the undamped dynamic response of composite structures may fail to improve, or may deteriorate, the dynamic performance near resonance, as they neglect the tailorable damping capacity of composite materials.

Overall, the application of the method on this primitive composite structure appeared very encouraging. Additional applications of the method on more complex structural configurations will be performed in the near future.

\section{References}

1. Saravanos, D. A. and Chamis, C. C., "Unified Micromechanics of Damping for Unidirectional Fiber Composites," Journal of Composites Technology and Research, Vol. 12, No.1, Spring 1990, in press.

2. Saravanos, D. A. and Chamis, C. C., "Mechanics of Damping for Fiber Composite Laminates Including Hygro-Thermal Effects," Proceedings, 30th AIAA/ASME/ASCE/AHS/ASC Structures, Structural Dynamics, and Materials Conference, Paper No. 89-1191-CP, Mobile, Alabama, Apr. 3-5, 1989.

3. Adams, R. D. and Bacon, D. G. C., "Effect of Fibre Orientation and Laminate Geometry on the Dynamic Properties of CFRP," Journal of Composite Materials, Vol. 7, Oct. 1973, pp. 402-428.

4. Ni, R. G. and Adams, R. D., "The Damping and Dynamic Moduli of Symmetric Laminated Composite Beams - Theoretical and Experimental Results," Journal of Composite Materials, Vol. 18, March 1984, pp. 104-121.

5. Siu, C. C. and Bert, C. W., "Sinusoidal Response of Composite-Material Plates with Material Damping," ASME Journal of Engineering for Industry, May 1974, pp. 603610.

6. Suarez, S. A., Gibson, R. F., Sun, C. T. and Chaturvedi, S. K., "The Influence of Fiber Length and Fiber Orientation on Damping and Stiffness of Polymer Composite Materials," Experimental Mechanics, Vol. 26, No. 2, 1986, pp. 175-184. 
7. Saravanos, D. A. and Chamis, C. C., "Computational Simulation of Structural Composite Damping," NASA TM, to appear

8. Liao, D.X., Sung, C.K. and Thompson, B.S., "The Optimal Design of Laminated Beams Considering Damping," Journal of Composite Materials, Vol. 20, 1986, pp. 485-501.

9. Hajela, P. and Shih, C. J., "Optimum Synthesis of Polymer Matrix Composites for Improved Internal Material Damping Characteristics," AIAA Journal, Vol. 26, No. 4, 1988, pp. 504-506.

10. Saravanos, D. A. and Chamis, C. C., "Tailoring of Composite Links for Optimal Damped Elasto-Dynamic Performance," Proceedings, ASME Design Automation Conference, Vol. No. H0509C, Montreal, Canada, Sept. 17-20, 1989.

11. Saravanos, D. A. and Chamis, C. C., "A Methodology for Optimizing Structural Composite Damping," Proceedings, Mechanics of Plastics and Plastic Components, Winter Annual Meeting of ASME, AMD-Vol. 104, Dec. 10-15, 1989, pp. 167-180.

12. Murthy, P.L.N. and Chamis, C.C., "ICAN: Integrated Composite Analyzer," AIAA Paper 84-0974, May 1984.

13. Vanderplaats G. N. "A Robust Feasible Directions Algorithm for Design Synthesis," Proceedings, 24th AIAA/ASME/ASCE/AHS Structures, Structural Dynamics, and Materials Conference, Lake Tahoe, NV, 1983.

14. Brown K. W., "Structural Tailoring of Advanced Turboprops (STAT) - Interim Report," NASA CR-180861, Aug. 1988. 
Table 1. Mechanical properties of HM-S/epoxy system. ( $70^{\circ} \mathrm{F}$ and $0 \%$ moisture)

\begin{tabular}{ll}
\hline \hline Epoxy & HM-S Graphite \\
\hline$E_{m}=0.500 \mathrm{Mpsi}$ & $E_{f 11}=55.0 \mathrm{Mpsi}$ \\
$\begin{array}{c}(3.45 \mathrm{GPa}) \\
G_{m}=0.185 \mathrm{Mpsi} \\
(1.27 \mathrm{GPa})\end{array}$ & $\left.E_{f 22}=0.9 \mathrm{GPa}\right)$ \\
$\psi_{m n}=10.30 \%$ & $\left.G_{f 12}=1.1 \mathrm{GPa}\right)$ \\
$\psi_{m s}=11.75 \%$ & $(7.6 \mathrm{GPa})$ \\
$\rho_{m}=0.0440 \mathrm{lb} / \mathrm{in}^{3}$ & $\nu_{f 12}=0.20$ \\
& $\psi_{f 11}=0.4 \%$ \\
& $\psi_{f 22}=0.4 \%$ \\
& $\psi_{f 12}=0.4 \%$ \\
& $\rho_{m}=0.0703 \mathrm{lb} / \mathrm{in}^{3}$ \\
\hline \hline
\end{tabular}


Table 2. Initial and optimum designs.

\begin{tabular}{|c|c|c|c|c|c|}
\hline \multirow[b]{2}{*}{ Thickness, (in) } & \multirow[t]{2}{*}{$\begin{array}{c}\text { Initial } \\
\text { Design }\end{array}$} & \multicolumn{3}{|c|}{$\begin{array}{l}\text { Single-Objective Designs } \\
\left.\operatorname{ain} F_{1}\right) \quad\left(\min F_{2}\right)\left(\min F_{3}\right)\end{array}$} & \multirow{3}{*}{$\begin{array}{c}\begin{array}{c}\text { Multi-Objective } \\
\text { Design }\end{array} \\
\\
\\
0.2584 \\
0.2343 \\
0.2329 \\
0.0400\end{array}$} \\
\hline & & & & & \\
\hline $\begin{array}{l}0 \% \text { span } \\
30 \% \text { span } \\
60 \% \text { span } \\
100 \% \text { span (tip) }\end{array}$ & $\begin{array}{l}0.2 \\
0.2 \\
0.2 \\
0.2\end{array}$ & $\begin{array}{l}0.2529 \\
0.2313 \\
0.2572 \\
0.1053\end{array}$ & $\begin{array}{l}0.2090 \\
0.2046 \\
0.1573 \\
0.0400\end{array}$ & $\begin{array}{l}0.2022 \\
0.2014 \\
0.2011 \\
0.1426\end{array}$ & \\
\hline Ply Angles, (de & rees) & & & & \\
\hline $\begin{array}{l}\theta_{1} \\
\theta_{2} \\
\theta_{3}\end{array}$ & $\begin{array}{l}0.0 \\
0.0 \\
0.0\end{array}$ & $\begin{array}{r}-26.28 \\
-27.80 \\
19.99\end{array}$ & $\begin{array}{r}-13.87 \\
-45.34 \\
23.17\end{array}$ & $\begin{array}{l}3.213 \\
3.678 \\
11.80\end{array}$ & $\begin{array}{l}-26.46 \\
-39.89 \\
-58.75\end{array}$ \\
\hline $\begin{array}{l}\text { Fiber volume r } \\
k_{f 1} \\
k_{f 2} \\
k_{f 3}\end{array}$ & $\begin{array}{l}\text { tios } \\
0.50 \\
0.50 \\
0.50\end{array}$ & $\begin{array}{l}0.632 \\
0.700 \\
0.116\end{array}$ & $\begin{array}{l}0.530 \\
0.478 \\
0.010\end{array}$ & $\begin{array}{l}0.482 \\
0.136 \\
0.010\end{array}$ & $\begin{array}{l}0.605 \\
0.010 \\
0.010\end{array}$ \\
\hline $\begin{array}{l}\text { Objective Func } \\
F_{1}(i n) \\
F_{2}(l b s) \\
F_{3}\left(i n^{3} / i n^{2}\right)\end{array}$ & $\begin{array}{l}\text { lons } \\
0.3977 \\
0.0677 \\
0.0990\end{array}$ & $\begin{array}{l}0.1361 \\
0.0758 \\
0.1114\end{array}$ & $\begin{array}{l}0.4467 \\
0.0520 \\
0.0685\end{array}$ & $\begin{array}{l}0.4399 \\
0.0576 \\
0.0492\end{array}$ & $\begin{array}{l}0.1580 \\
0.0609 \\
0.0486\end{array}$ \\
\hline$\underset{u_{s y}}{\text { Max. }}$ & $\begin{array}{c}\text { ic defle } \\
19.70\end{array}$ & $\begin{array}{l}\operatorname{tion}(\mathrm{tip}) \\
21.24\end{array}$ & $\begin{array}{r}\left.10^{-3} \mathrm{in}\right) \\
35.00\end{array}$ & 24.38 & 30.69 \\
\hline $\begin{array}{l}\text { Natural Freque } \\
f_{1} \\
f_{2} \\
f_{3}\end{array}$ & $\begin{array}{c}\text { cies, }(\mathbf{H} \\
387.4 \\
1095.3 \\
1549.7\end{array}$ & $\begin{array}{r}400.2 \\
1462.3 \\
2321.7\end{array}$ & $\begin{array}{r}485.6 \\
1971.0 \\
2010.4\end{array}$ & $\begin{array}{r}400.0 \\
1200.0 \\
1367.0\end{array}$ & $\begin{array}{r}421.2 \\
1362.2 \\
2177.1\end{array}$ \\
\hline $\begin{array}{l}\text { Resonance } \mathbf{y - a x} \\
U_{y 1}^{r} \\
U_{y^{2}}^{\tau} \\
U_{y 3}^{\tau}\end{array}$ & $\begin{array}{l}\text { Ampli } \\
0.3977 \\
0.0000 \\
0.0000\end{array}$ & $\begin{array}{c}\text { udes (tip } \\
0.136 \\
0.000 \\
0.005\end{array}$ & $\begin{array}{l}\text { (in) } \\
0.450 \\
0.002 \\
0.071\end{array}$ & $\begin{array}{l}0.443 \\
0.000 \\
0.000\end{array}$ & $\begin{array}{l}0.1577 \\
0.0000 \\
0.0102\end{array}$ \\
\hline $\begin{array}{l}\text { Modal SDC's, } \\
\psi_{1} \\
\psi_{2} \\
\psi_{3}\end{array}$ & 7) $\begin{array}{l} \\
0.604 \\
5.592 \\
3.503\end{array}$ & $\begin{array}{l}1.881 \\
3.374 \\
2.287\end{array}$ & $\begin{array}{l}0.807 \\
1.387 \\
0.869\end{array}$ & $\begin{array}{l}0.654 \\
5.251 \\
2.992\end{array}$ & $\begin{array}{l}2.238 \\
3.769 \\
2.533\end{array}$ \\
\hline
\end{tabular}




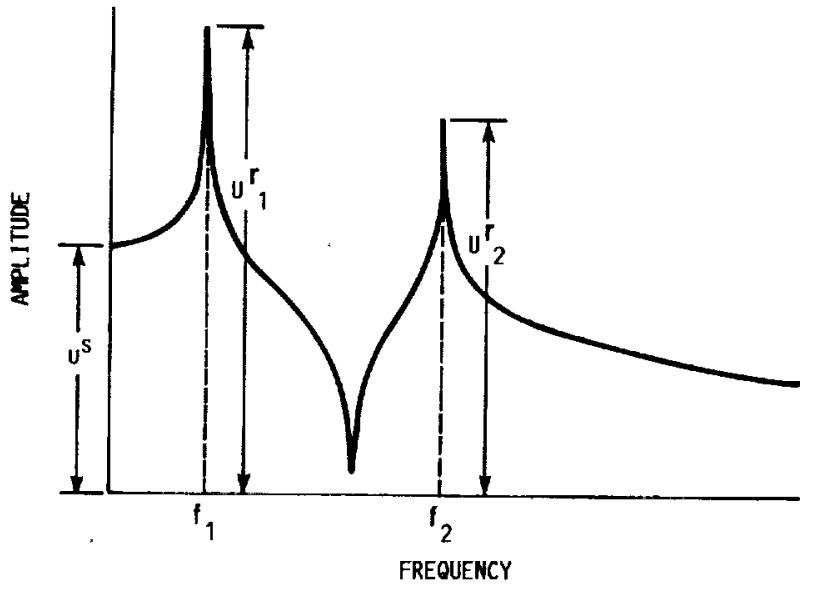

FIGURE 1. - TYPICAL FREQUENCY RESPONSE FUNCTION.

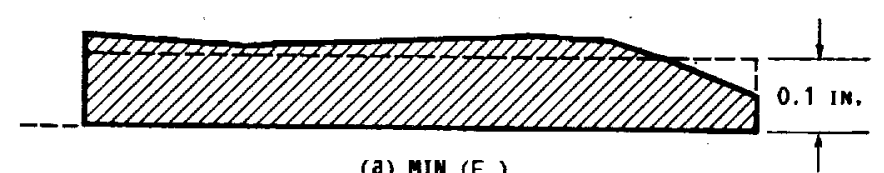

(a) $\operatorname{MIN}\left(F_{1}\right)$.
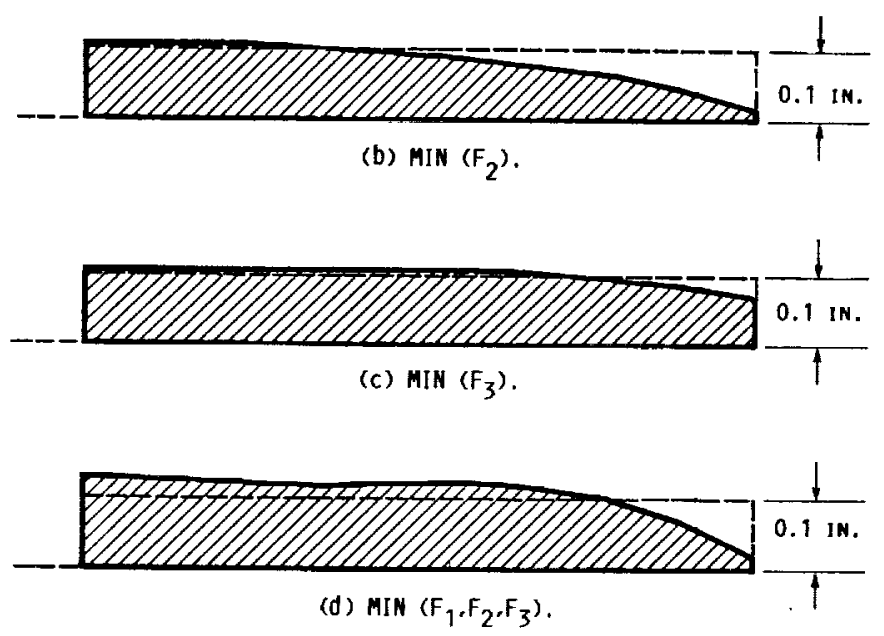

FIGURE 3. - INITIAL AND OPTIMUM THICKNESS DISTRIBUTIONS.

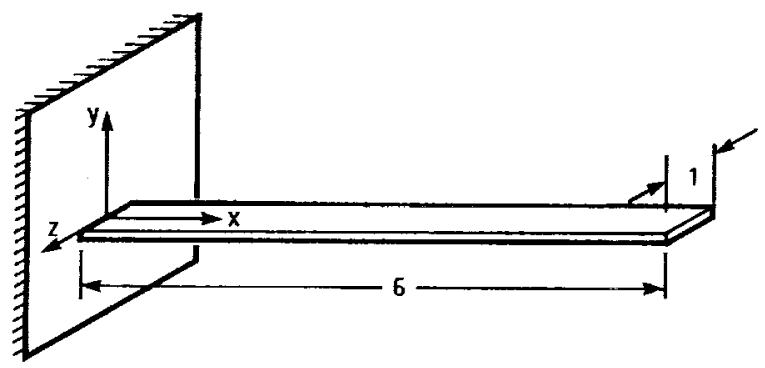

(a) INITIAL GEOWETRY.

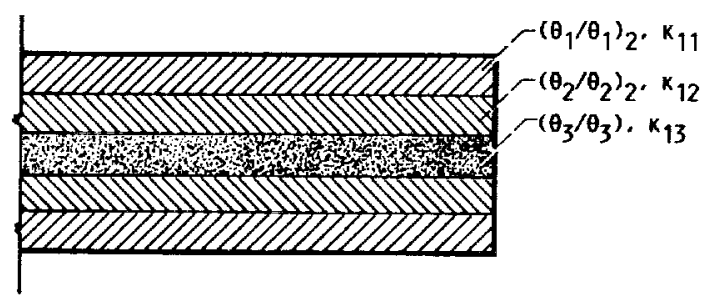

(b) LAMINATE CONFIGURATION.

FIGURE 2. - CANDIDATE COMPOSITE BEAM.

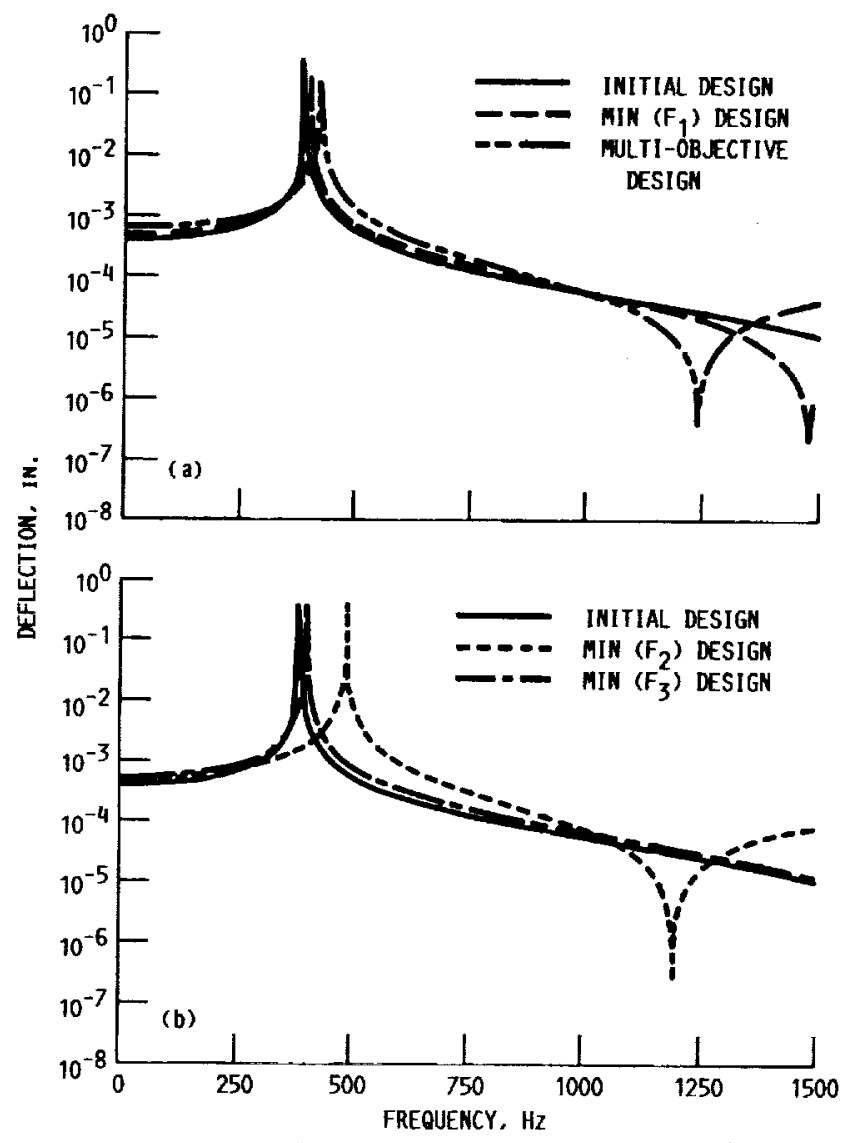

FIGURE 4, - FREQUENCY RESPONSE FUNCTIONS OF THE INITIAL AND OPTIMAL DESIGNS. 


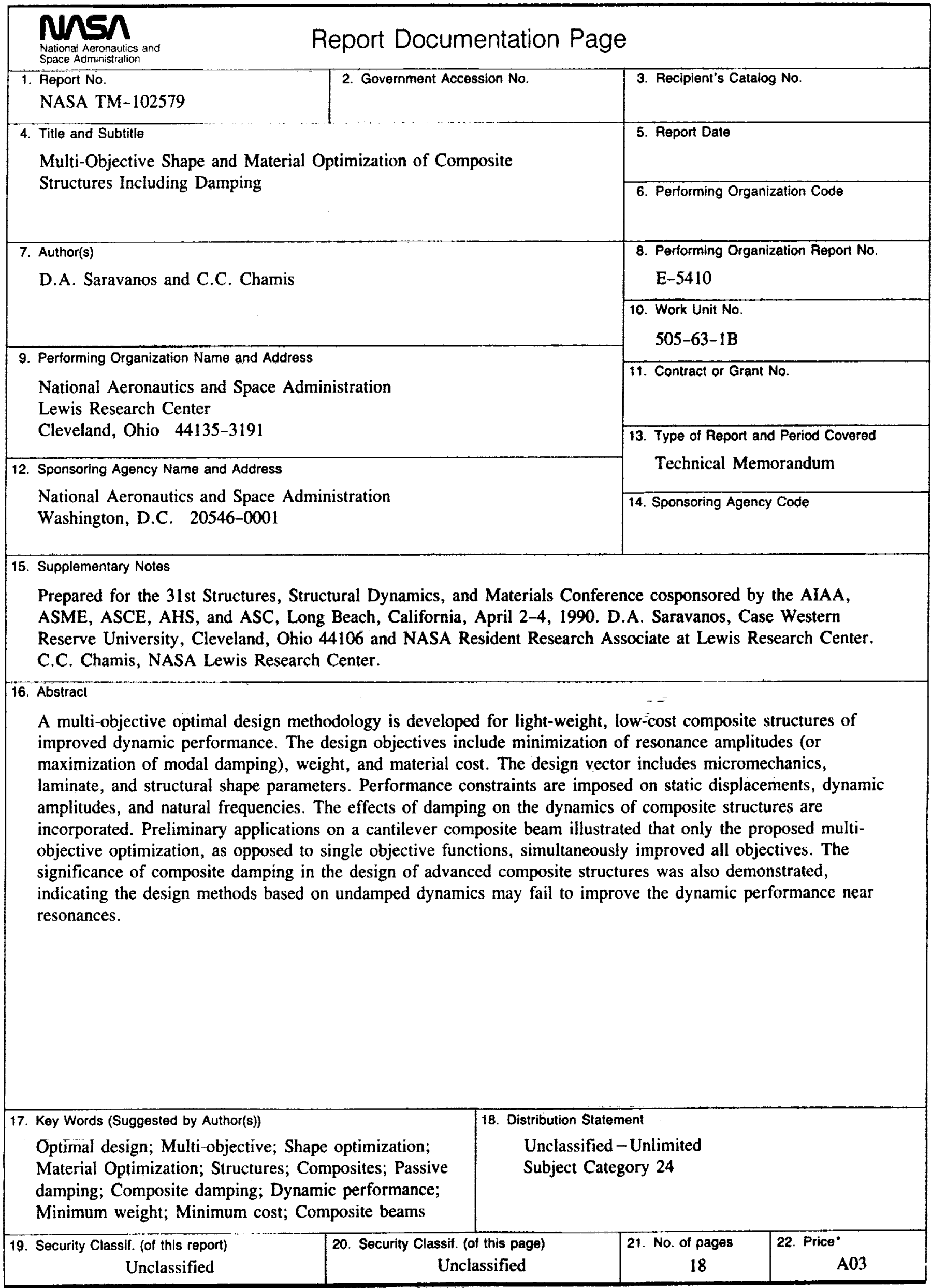

